\title{
Should Merchant Transmission Investment be Subject to a Mustoffer Provision?
}

\author{
Gert Brunekreeft and David Newbery
}

August 2005

CWPE 0534 and EPRG 03

These working papers present preliminary research findings, and you are advised to cite with caution unless you first contact the author regarding possible amendments. 


\title{
Should Merchant Transmission Investment be subject to a Must- offer Provision? ${ }^{1}$
}

21 July 2005

\author{
GERT BRUNEKREEFT \\ Tilburg University \\ TILEC \\ PO Box 90153, 5000 LE TILBURG, The Netherlands \\ E-mail: G.Brunekreeft@uvt.nl \\ DAVID NEWBERY \\ University of Cambridge \\ Faculty of Economics \\ Sidgwick Ave, Cambridge CB3 9DE, England \\ E-mail:dmgn@econ.cam.ac.uk
}

\begin{abstract}
:
Merchant electricity transmission investment is a practically relevant example of an unregulated investment with monopoly properties. However, while leaving the investment decision to the market, the regulator may decide to prohibit capacity withholding with a must-offer provision. This paper examines the welfare effects of a must-offer provision prior to the capacity choice, given three reasons for capacity withholding: uncertainty, demand growth and pre-emptive investment. A must-offer provision will decrease welfare in the first two cases, and can enhance welfare only in the last case. In the presence of importer market power, a regulatory test might be needed.
\end{abstract}

Key words: investment, must-offer, capacity withholding, regulation, electricity JEL Classification: L51, L94, L4

\section{INTRODUCTION}

Economists are alert to the potential inefficiencies of regulation, and have devoted considerable effort to devising market mechanisms that might reduce some of these inefficiencies. The high pressure gas network in Britain (the National Transmission System) operates under regulated Third Party Access (rTPA, considered the best form of regulation, and now required by the 2003 EU Energy Directives) but in the past this required the regulator to set the transmission tariffs. The form chosen was an entry and exit capacity charge that could (and did) give rise to serious problems of efficient rationing in the presence of excess entry demand. The solution, which worked well, was to adopt auctions for entry capacity while continuing to set exit charges according to long-run marginal cost (McDaniel and Neuhoff, 2004). For similar reasons, electricity transmission lines are best subject to

\footnotetext{
${ }^{1}$ The authors are grateful to Pio Baake, three anonymous referees and the participants of a seminar at TILEC at Tilburg University for useful comments and discussion. Support from the CMI project 045/P Promoting Innovation and Productivity in Electricity Markets is gratefully acknowledged.
} 
rTPA, but the EU Regulation on Cross-border Exchange (EC, 2003) requires that congestion management should use "market-based solutions" such as auctions.

Using auctions to allocate access to existing scarce natural monopolies is efficient, provided there are sufficiently many users wishing access, and this has encouraged regulators to explore market-based solutions for guiding investment decisions in such natural monopolies, although this turns out to be considerably more difficult (Newbery and McDaniel, 2003). This paper explores a particular solution to this problem, in which private investors are invited to construct electricity transmission lines in return for the rights to the revenue created by the spot price differential across the line. These market prices would therefore signal the need for, and provide the revenue to, finance that investment, reducing the cost to final consumers of mistaken regulated investment.

In the past vertically integrated companies (either state-owned or regulated utilities) invested in transmission to meet specified security standards and to deliver power efficiently. In liberalised markets transmission must not only ensure network integrity and reliability, but must also respond to the needs of generators who are no longer under the control of the utility. Regulated transmission system operators (TSOs) are still responsible for managing and maintaining the existing network, and for investments that pass a regulatory test, and whose costs can therefore be recovered from regulated transmission charges. Wholesale electricity markets now open new opportunities for transmission investment, as they provide opportunties for wheeling power from low price to high price locations. The resulting revenue makes it possible to contemplate merchant transmission investment (MTI), and as a result many jurisdictions now allow third parties to invest in transmission.

Merchant transmission projects are already operating in the USA and Australia, and are under consideration in Europe. There is a difference between the USA on the one hand and Europe and Australia on the other. The nodal pricing approach for congestion management in the USA allows for a rather refined approach towards MTI, as prices differ by nodes, and point-to-point incremental Financial Transmission Rights can be designed to internalise network effects induced by loopflows. ${ }^{2}$ The rather crude zonal or regional pricing approach for congestion management in Europe and Australia restricts MTI to inter-regional interconnectors operating with direct current (DC) technology. High voltage DC (HVDC) interconnectors are controllable and can thus prevent unwanted loop flows. These interconnectors connect two different networks and are rewarded by the price differentials between the two ends of the line. ${ }^{3}$

This paper considers the regulatory issues that arise in the European and Australian context. For this setting the Australian ACCC provides the following useful definition of MTI as transmission investment "operating between two connection points assigned to different regional reference nodes, [..] supported by the revenue stream generated by trading electricity between the two interconnected regions, [and] not eligible to earn regulated revenue."

\footnotetext{
${ }^{2}$ Cf. Bushnell \& Stoft [1996], Joskow \& Tirole [2005], Hogan, [2003], Rosellón [2003] and Kristiansen \& Rosellón [2003].

${ }^{3} \mathrm{Cf}$ for a more detailed treatment Brunekreeft [2004].
} 
[ACCC, 2001, p. 126]. Note in particular that this means that the market-based revenues are unregulated and the same time that the investor is not eligible to regulated (non-user-specific) connection charges.

The regulatory debate has been provoked in Europe by the proposed BritNed interconnector. BritNed is a $200 \mathrm{~km}$ long subsea HVDC cable connecting the United Kingdom and the Netherlands, planned to be operational in 2007. The original planned capacity was $1320 \mathrm{MW}$, but this was revised to $600 \mathrm{MW}$. BritNed is a legally separate subsidiary, fully owned by the TSO in the UK, National Grid Company (NGC) and the TSO in the Netherlands, TenneT. The construction costs are estimated at about $€ 350$ million, partly funded by the EU's program on trans-European networks (TEN). Revenues will be derived predominantly from trading between the two power exchanges (the UKPX in London and APX in Amsterdam). Depending on various assumptions, the profitability has been calculated between 7 and 23\% [Newbery, Von der Fehr \& Van Damme, 2003, p. 8]. Due to perceived high risk, the project is becoming increasingly uncertain. The first merchant EU interconnector to go ahead is Estlink connecting the Baltic States and Finland. The European Commission approved the regulatory exemption already granted by the electricity regulatory authorities in Estonia and Finland, which provided the necessary assurances to the banks and investors.

The legal framework for European MTI is laid down in the EU Regulation on Crossborder Exchange (EC, 2003), which entered into force on 1 July 2004. Art. 7 of the Regulation allows new interconnectors to be exempted from regulated third party access, although under rather stringent conditions. These include that the project should enhance competition in electricity supply, and that exempting it from regulation does not adversely affect the efficient functioning of the electricity market or the regulated transmission system. In addition, the project must be risky, legally separated from the TSOs of the systems it interconnects, and must be DC (except where DC is prohibitively expensive as compared to the more normal AC). The requirement that the project should be risky to qualify for exemption is important as will become clear below.

Why would one want to allow unregulated MTI in the first place? After all, transmission investment remains a classic natural monopoly requiring regulation to prevent consumer exploitation and to assure independent generators of equal access to the market. There is clearly an attraction of replacing regulation by market forces where possible, although in the past the public good nature of most network investment has made this problematic for transmission investment. The main reason for opening transmission investment to profit-motivated merchant investors is that this may go some way to addressing the perceived problem of under-investment in transmission, particularly between systems under different TSOs. Such under-investment can arise for three reasons. First, vertically integrated utilities, owning both generation and transmission assets, have relatively poor incentives to interconnect their systems. Stronger interconnection will give some gains from trade, but increases competition in their respective generation markets and may reduce profits. If vertical separation of transmission from generation is not feasible, an alternative approach to this problem is to allow third parties to invest in transmission assets. 
The second reason is that a new interconnector will as a rule decrease prices on the importing side, but increase prices on the exporting side. If agencies at each end of the line are authorised to grant or with-hold permission to build the line, the losing side may be tempted to block construction of the line although the line might be globally welfare enhancing. One approach to this problem is to reduce the thresholds for approval and thereby reduce the authority of the agencies. Under market-based investment commercial feasibility is the ultimate criterion which is for the investors to decide.

The third reason was extensively discussed in Australia and well summarised in Gans \& King [2003]. The argument relies on regulatory uncertainty concerning risky new investment and the inability of regulators to commit credibly to refrain from "clawing back" revenues after the investment has been sunk. ${ }^{4}$ Suppose that the rate of return of the risky investment in case of a bad state of the world is $6 \%$, but $14 \%$ in a good state. If both states have equal probability the risk-equivalent expected return would be $10 \%$, which might serve as the agreed base for the regulated prices. At some point, usually after 3 to 5 years, a review sets out the rules for the price caps for the next round. The argument is that a regulator will not modify its original views if the state of the world is bad, while the regulator will be tempted to strengthen rate regulation if the world turns out to be good. Assume that the regulator might reduce the allowed prices such that the rate of return is $10 \%$ if the good state occurs. Anticipating this, the expected rate of return is $8 \%$ rather than the required $10 \%$. It is straightforward to see that this may lead to underinvestment or abandoning the project. It is argued that credibility to refrain from intervening is increased by not regulating the risky new investment at all (for a predetermined number of years) by granting a "regulation holiday".

The emergence of unregulated market-based transmission investment raises a set of regulatory issues. Some of these have been explored by the Dutch electricity regulator in anticipation on BritNed [Newbery, Von der Fehr \& Van Damme, 2003; Brunekreeft, 2005]. The questions raised concern ownership, the access regime, the appropriate share of longterm versus short-term access rights, and the application of a must-offer or use-it-or-lose-it provision. The EU Regulation mentioned above sets the rules for these provisions. Perhaps surprisingly, given the reasons for relaxing regulation, art. 7 does not exempt new interconnectors from arts. 6.3 and 6.4. Art. 6.3 states that: "the maximum capacity of the interconnector [..] shall be made available to market participants [..]", and art 6.4 amplifies this: " [..] any allocated capacity that will not be used shall be reattributed to the market, in an open, transparent and non-discriminatory manner."

For the purpose of this paper, these articles will be called a must-offer provision (art. 6.3) and a use-it-or-lose-it provision (art. 6.4) respectively. These will be abbreviated with MO and UIOLI respectively. The distinction we draw between the two is that MO applies to the owner of the interconnector, who must offer all of the capacity available to capacity holders, while UIOLI applies to the subsequent holders of capacity rights, who have their rights returned to the (capacity rights or interconnector auction) market if they are not

\footnotetext{
${ }^{4}$ In the context of price-cap regulation in general the issue has been discussed in for instance Helm \& Thompson [1991] and Gilbert \& Newbery [1994].
} 
declared to the System Operators a certain number of hours or days in advance of the relevant time. The practical distinction is that the owner is in a position to exercise market power by withholding capacity from the market in certain periods, while capacity holders may be too numerous for it to be attractive for any single user to withhold capacity, even though collectively it would be profitable to withhold capacity.

This paper addresses the question whether it can be desirable for merchant investors to be allowed to withhold capacity from the market, that is, whether to waive the MO provision under some circumstances. The basic trade-off is that an MO provision may forestall capacity withholding of an already-constructed interconnector and thereby increase short term welfare, but may have a detrimental effect on the investment (in size and timing). ${ }^{5}$ The concept of must-offer provision is relatively new and has not received much attention. One prominent application is in power generation in the USA where the federal regulator tries to identify (abuse of) market power via observed capacity withholding. Harvey and Hogan [2001] provide a critical assessment of this policy, by pointing out that capacity withholding also occurs in competitive markets.

As noted, the distinction between MO and UIOLI refers to the two different levels at which capacity utilisation should be considered. The first applies to the decision of the investor about the size of the line, while the second applies to the decisions by the users of the line. If the investor sells off capacity rights to use the line, these decisions differ. The open-access regime in the USA with the requirement to auction off the (financial) transmission rights emphasises this difference. In the Australian safe-harbour-approach it is left to the line owner to decide whether or not to sell usage rights and as a result the access question is left to the line owner; thus owner and user can, but need not, be the same. Europe seems more likely to follow the Australian approach, because art. 7 of the EU Regulation can exempt the new interconnector from (regulated) Third Party Access. ${ }^{6}$ The term must-offer will be reserved for the line owner and thus to the allocation of the capacity rights. ${ }^{7}$ A mustoffer provision then simply means that all available capacity should be offered in the market, or in other words, that capacity withholding is not allowed.

The two provisions are distinct but related, as follows. The theory of vertical relations is helpful, where the investor-level is denoted upstream, and the user-level downstream. ${ }^{8}$ Three points are worth noting. First, an upstream MO provision may also require a downstream UIOLI rule. Otherwise the upstream line owner will attempt to offer all the rights to the single highest bidding user, who will then internalise the profits of capacity withholding and pay for this with the winning bid. Whether this is possible depends crucially

\footnotetext{
${ }^{5}$ The articles 6(3) and 6(4) have been included for existing interconnectors, but because art. 7 does not exempt new interconnectors from these articles, they carry over to new interconnectors. Since a provision like that will in general affect the investment decision, the difference between existing and new interconnectors is significant.

${ }^{6}$ Whether this exemption applies to the "third party access" requirement or only to "regulated" requirement remains an open question.

${ }^{7}$ Concerning the allocation of the line's capacity it is unclear "what is lost if not used"; hence, the term MO would be unfortunate for the allocation of the capacity rights.

${ }^{8}$ See e.g. Perry [1989] for a survey and Brunekreeft [2002] for an application to the unregulated and vertically integrated German electricity supply industry
} 
on the details of the auction [cf. Joskow \& Tirole, 2000; and Grossman \& Hart, 1980]. This is equivalent to leveraging market power. Second, if there is no MO provision, then it will generally be in the interest of the line owner to secure maximum profits either by withholding capacity at the upstream level or securing the possibility to do so at the downstream level. Hence, a downstream UIOLI rule will be superfluous. Third, if there is a downstream UIOLI rule, then an MO provision should be applied as well; otherwise the downstream UIOLI rule would likely be by-passed at the upstream level. Whether that is possible depends on the design of the usage rights. The line owner would not be able to withhold capacity if all capacity were sold off on long-term contracts. However, if a sufficiently large fraction of capacity is reserved as short-term contracts, or even spot capacity, then the line owner does have the possibility to withhold capacity.

A related point is whether these provision can be enforced at all. First, there might be legitimate reasons why not all capacity can be offered at some point, for instance for maintenance and unforeseen outages. These reasons can be exploited strategically to withhold capacity. However, these concerns appear more problematic with generation assets than with transmission assets that are normally far more reliable. Second, the capacity may be offered at prohibitively high prices at which there is no demand. This seems most likely at the user level. Suppose there is one single user with all the capacity rights. This user can withhold capacity by offering the imported energy (for which the capacity rights are used) in the energy market at a prohibitively high price; as a result of lacking demand this capacity would not be scheduled and in effect capacity would be withheld. This is likely to be more problematic in a (pay-as-bid) auction for spot interconnection capacity. In the context of generators' must-offer rules in the USA, this very real problem triggers a bid-pricing analysis by FERC: strategic withholding is said to occur if bids are higher than both the full incremental costs and the market price [cf. Harvey \& Hogan, 2001, p. 15]. This argument loses relevance if there is sufficient competition among the line users.

Whether an MO provision is enforceable depends on pricing. Registered prices (i.e. the line owner simply sets a price) can be prohibitively high, whereas an auction would require a prohibitively high reservation price. In any case, prohibitively high prices may arouse suspicions of abuse of market power and attract attention, but at the same time given that the revenues are unregulated this will be quite hard to identify, particularly if the capacity is sold for different periods. Thus it may be reasonable to set a very high reservation price for peak hours in high demand periods, and a far lower price for night-time use. If the object in allowing merchant investment is to address under-investment in interconnection, it would seem perverse to restrict the opportunities to earn sufficient profits to make the lumpy investment worthwhile. For the moment we leave these wider competition policy issues on one side and concentrate on an MO provision (implicitly assuming that the line owner is the single user of the line) and assume that the provision is enforceable.

The paper considers a variety of cases to determine whether there are robust regulatory rules about when to impose MO and when to waive the MO provision. In the simplest case discussed first, the only relevant source of market power lies in the control of the interconnector. In the second case the importing country also suffers from market power. 
Within each of these cases there are a variety of reasons for, and possible patterns of trade over, the interconnector. It may be that flows are always in one direction, from a permanently surplus low cost producer, or they may vary in direction depending on the time of day or season (e.g. from a storage hydro system such as Norway to a thermal system such as the Netherlands). Import demand may vary about an unchanged average or evolve over time, raising questions of investment timing as well as amount.

The simplest case to consider is where the only relevant market power lies with the owner of the interconnector and the line always imports. Generators in the importing country behave competitively, so the line owner faces a residual demand schedule. As a further simplification the costs of importing power (purchase cost abroad and any transmission losses) are normalised to zero (i.e. the relevant domestic price is the excess over the import cost). The actual cost of cheap imported power only makes a difference if there are generators in the importing market with different marginal costs. While these two simplifications sacrifice realism they do allow us to concentrate on the effects of an MO provision applied to the line, which will be the primary aim of section 2 . Section 3 will relax the assumptions.

In order to analyse the effects of an MO provision, the reasons for capacity withholding need first to be identified. Given that revenues are unregulated, and given that the capacity decision still has to be made, it is not immediately obvious why capacity withholding would be a profitable strategy. We examine three reasons for possible capacity withholding:

i) Demand uncertainty and demand variability (i.e. predicted variations in the determinants of the spot price);

ii) demand growth; and

iii) pre-emptive investment.

The conclusions are as follows. If demand uncertainty is the driver for capacity withholding, an MO provision is unambiguously weakly welfare decreasing. Furthermore, an MO provision unambiguously delays new investment and decreases the capacity in anticipation of demand growth; while numerical analysis suggests that it decreases welfare. If pre-emptive investment is the determinant of the line capacity, then an MO provision is likely to increase welfare. If the line owner competes against generators on the importing side, their market power on the energy market drives a wedge between cost and price in the importing market. An interconnector can exploit this wedge even if the importing cost is higher than in the importing market. Thus in such case MTI may be welfare decreasing.

\section{MONOPOLY INTERCONNECTOR, COMPETITIVE ELECTRICITY MARKETS}

\subsection{Demand uncertainty}

One of the important arguments for not regulating MTI is the risk that if regulated, the investor fears that he would lose the upside gains from risky new investment but bear the downside losses. Risk requires some source of uncertainty that is modelled as (residual) demand uncertainty. Demand uncertainty also provides a motive for capacity withholding. 
With ex ante demand uncertainty it may a profitable strategy to choose capacity for demand states in which the residual demand elasticity is high and withhold capacity in cases where the demand elasticity is low. That would be profitable if the monopoly output were below full capacity. This situation can be countered with an MO provision, which, however, will affect the investment decision.

This section considers the case of linear (residual) demand but fairly general demand uncertainty. The results are strong and likely to generalise to a wider class of demand functions. The costs of building the line are assumed to be:

$$
C(K)=F+\beta \cdot K,
$$

where $K$ is the capacity of the line, $F$ is the fixed and $\beta$ the variable construction costs (expressed as hourly equivalents, so that, for example, when $K$ is measured in $\mathrm{MW}, \beta$ will be a cost per MWh). The operational output of the line is $Q$, with $Q \leq K$. An MO provision requires $Q=K$.

The inverse demand schedule is

$$
p_{s}=a_{s}-b_{s} Q_{s}, \quad Q_{s}<a_{s} / b_{s}, \text { for } \mathrm{s}=\mathrm{L}, \mathrm{H} .
$$

where $p_{s}$ is the price difference across the interconnector in state of the world $s, Q_{s}$ is the flow over the interconnector $\left(Q_{s} \leq K\right)$ and the price difference (for any level of demand) is high in state of the world $s=H$, and low in state of the world $s=L$. The condition on $Q_{s}$ ensures that the efficient price never falls to zero. ${ }^{9}$ Let $\alpha_{s}$ be the probability of state $s$, with $\Sigma \alpha_{s}=1$. Let the expected values of the state-dependent parameters take their unsubscripted values, thus $\mathrm{E} a_{s}=\Sigma \alpha_{s} a_{s}=a$, and similarly $\mathrm{E} b_{s}=b$.

\section{The MO provision}

The line investor's objective is to choose capacity and output to maximise profits:

$$
\underset{Q_{s}, K}{\max } \pi_{s}=\sum_{s} \alpha_{s} p_{s}\left(Q_{s}\right) Q_{s}-\beta K \quad \text { s.t. } \quad Q_{s} \leq K .
$$

The Lagrangean is

$$
L=\sum_{s} \alpha_{s} p_{s}\left(Q_{s}\right) Q_{s}-\sum_{s} \lambda_{s}\left(Q_{s}-K\right)-\beta K
$$

and the respective first order conditions are:

$$
\begin{gathered}
\frac{\partial \pi}{\partial Q_{s}}=\alpha_{s}\left(\frac{\partial p_{s}}{\partial Q_{s}} Q_{s}+p_{s}\right)-\lambda_{s}=0, \forall s, \\
\frac{\partial \pi}{\partial K}=\sum_{s} \lambda_{s}-\beta=0 .
\end{gathered}
$$

\footnotetext{
${ }^{9}$ It is easy to relax this condition, and the results mirror those of section 2.2.
} 
Note that capacity utilisation $Q$ is determined after the state of the world is known, whilst the investment decision is made under uncertainty. Sum over equation (5) and use (6) to give the interpretation that the expected marginal revenue is equal to the long-run marginal cost of capacity, $\beta$. We need to check that at the profit maximising choice of outputs, revenue is sufficient to cover the total capacity cost, $C(K)$. For that we need to calculate output levels and revenue, which is done below.

We contrast three cases: the case in which capacity can be withheld from the market, the case of no capacity withholding, or MO, and the welfare maximising choice of $K$ and $Q$. At this stage we do not know in which state of the world it might be profitable to withhold capacity, so define that state as state $s=w$ (for withholding) and the state in which the capacity constraint binds as state $s=c$ (for capacity constrained). ${ }^{10}$

Capacity withholding: In this case the shadow price of capacity in that state is zero: $\lambda_{w}=0$, hence $\lambda_{c}=\beta$ from (6). Solving (5) and (6) gives:

$$
\begin{gathered}
Q_{w}=\frac{a_{w}}{2 b_{w}}, \\
Q_{c}=K=\frac{a_{c}}{2 b_{c}}-\frac{\beta}{2 \alpha_{c} b_{c}} .
\end{gathered}
$$

No capacity withholding (MO): In this case the capacity constraint binds (weakly) in all (both) demand states and $Q_{s}=K$ for all $s$. Solving (5) and (6) gives the value for $K=K^{N}$ :

$$
Q^{N}=K^{N}=\frac{a-\beta}{2 b} \text {. }
$$

If the line owner chooses not to withhold capacity even if allowed, then the MO condition is not binding. In that case $Q_{w}=Q_{c}$. If capacity withholding is profitable it must be that $Q_{w}<Q_{c}$, which requires that

$$
\frac{a_{w}}{2 b_{w}}<\frac{a_{c}}{2 b_{c}}-\frac{\beta}{2 \alpha_{c} b_{c}}
$$

i.e.

$$
\beta<\alpha_{c} b_{c}\left(\frac{a_{c}}{b_{c}}-\frac{a_{w}}{b_{w}}\right)=\alpha_{c} b_{c} Q\left(\varepsilon_{c}-\varepsilon_{w}\right) \equiv \mathrm{B}^{*},
$$

where $\varepsilon_{s}$ is the elasticity of demand in state $s$ (as a positive number) measured at a reference output level $Q$. Capacity withholding is therefore only profitable if the residual demand

\footnotetext{
${ }^{10}$ We follow the convention that superscripts refer to types of equilibrium and subscripts to states of the world, and in this section that superscript $N$ means $N o$ capacity withholding, and an asterisk refers to the social optimum.
} 
schedule is less elastic in one state (the state in which it may be profitable to withhold capacity). Withholding capacity is more likely the lower is the marginal cost of capacity expansion, $\beta$, the lower is the likelihood of a state of the world in which capacity may be profitably withheld, $\alpha_{w}=1-\alpha_{c}$, and the larger is the absolute difference in the demand elasticities in the two states.

The least favourable case for covering fixed costs is MO, and the condition for positive net profits is then $\mathrm{E}_{s} K^{N}>C\left(K^{N}\right)$, or, substituting from (1) and (9), $(a-\beta)^{2}>4 b F$. We assume that this is satisfied in what follows.

\section{Social welfare maximising case.}

In this case the expected price (rather than the expected marginal revenue) is equal to the LRMC of capacity: $\Sigma \alpha_{s} p_{s}=\beta,{ }^{11}$ and $Q_{s}=K$ in all states, so that:

$$
\sum_{s} \alpha_{s} p_{s}=\sum_{s} \alpha_{s}\left(a_{s}-b_{s} K\right)=\beta
$$

and so

$$
K^{*}=\frac{a-\beta}{b}=2 K^{N}
$$

This demonstrates that given a choice (and assuming no threats from pre-emption), merchant investment will be less than the efficient level $K^{*}$ (and in the case of linear demand only half the efficient level).

The main result of this section is that in this case, if line owners are free to withhold capacity and choose to do so, social welfare will be higher than if they are prevented from withholding capacity, i.e. are subject to an effective MO provision.

Proposition 1. Under ex ante demand uncertainty, social welfare is weakly higher with capacity withholding than under MO.

Proof: We need to prove that social welfare without an MO provision $(S W)$ should be larger than the case with an MO provision or No withholding $S W^{N}$. Using the same notation as before (subscript $w$ for the state of lower output and $c$ for capacity output):

$$
\Delta S W=\alpha_{w} S W_{w}+\alpha_{c} S W_{c}-S W^{N}-\beta\left[Q_{c}-Q^{N}\right]
$$

Next evaluate the change in social welfare at optimized quantities by taking the total differential wrt $\beta$. Define $\Gamma(\beta)$ for $\mathrm{d} \Delta S W(\beta) / \mathrm{d} \beta$. We will show that $\Gamma(\beta)<0$, for $\beta<\mathrm{B}^{*}$. This means that if capacity withholding is profitable, it also increases welfare. Under linear demand $S W_{s}=1 / 2\left(a_{s}+p_{s}\right) Q_{s}$. The optimized quantities are as in (7) to (9). Note that

\footnotetext{
${ }^{11}$ This can be established by replacing revenue $p_{s} Q_{s}$ in (4) by utility $U\left(Q_{\mathrm{s}}\right)$, whose derivative with respect to $Q_{s}$ is the price in that state, $p_{s}$.
} 
$p^{N}=a-b Q^{N}$, with $a$ and $b$ defined as before, and that $Q_{w}$ and $p_{w}$ do not depend on $\beta$. Substituting, differentiating w.r.t. $\beta$ and simplifying gives:

$$
\Gamma(\beta)=\frac{3}{4}\left[\left(\frac{a-\beta}{b}\right)-\left(\frac{\alpha_{c} a_{c}-\beta}{\alpha_{c} b_{c}}\right)\right] .
$$

This expression has straightforward properties. Note that

$$
\frac{d \Gamma(\beta)}{d \beta}=\frac{3}{4}\left[\frac{1}{\alpha_{c} b_{c}}-\frac{1}{b}\right]>0 \text { and } \frac{d^{2} \Gamma(\beta)}{d \beta}=0 .
$$

Moreover, substituting $\beta=\mathrm{B}^{*}$ from (11) gives $\Gamma=0$. This implies that $\Gamma$ is linearly increasing in $\beta$ and is uniquely zero at $\beta=\mathrm{B}^{*}$. Hence, for $\beta<\mathrm{B}^{*}, \Gamma<0$. Starting from $\beta=\mathrm{B}^{*}$, where the cases exactly meet, decreasing $\beta$ slightly would trigger capacity withholding which improves welfare. This continues to be the case. For the case, $\beta>\mathrm{B}^{*}$ the outcomes of the two cases overlap and hence social welfare is the same for both cases. In total, the MO provision weakly decreases social welfare. QED.

The intuition is straightforward. Depending on parameters, the firm may find it profitable to speculate on the high-demand case and invest in a sufficiently large capacity; if ex-post demand is low, then the output will be reduced below capacity. A must-offer provision makes the low-demand case less profitable and will in effect induce the firm to reduce invested capacity to restore the balance between high- and low-demand marginal profits. A must-offer provision thus increases social welfare in the low demand state, but reduces social welfare in the high demand state. On balance, the must-offer provision decreases social welfare. Overall, demand uncertainty bears a close relation to the analytical framework of peak-load pricing as in Steiner [1957]. This also implies that demand variability is covered by the analysis.

It may be emphasised that this case appears to be relevant. Risky investment is one of the arguments underlying the discussion on unregulated MTI in the first place and is one of the preconditions to qualify for the exemption from regulation in the EU Regulation. It seems only consistent that if risk is the reason for refraining from regulation, that the same argument should apply with respect to an MO provision.

\subsection{Demand growth}

Predictable demand growth raises more complex questions, as now merchant investors must choose the timing and capacity of the interconnector, both of which are likely to be influenced by any MO requirements (and the design of any initial open seasons auctions). The simplest case that captures the spirit of demand growth without unbounded growth in price differentials would be 


$$
p(t)=a-b e^{-g t} Q(t), Q(t) \leq a e^{g T} / b,
$$

where again $p(t)$ is the price at date $t$. This has the agreeable property that anchanged price, $p$, demand grows at a steady rate $g$. In the simplest case there is only one investor who makes a single investment decision.

\section{Merchant investment under an MO provision}

If the investment decision is made under $\mathrm{MO}$, then $Q(t)=K$, for all $t \geq T$, the date of opening of the interconnector, provided that $K \leq a e^{g T} / b$, otherwise the price would fall to zero until demand rose sufficiently. An investor (at least one not concerned with any threat of preemption) would not choose to invest excessively or prematurely under MO, as profits would be zero until the capacity constraint binds, but costs would be incurred unnecessarily soon. Using the notation superscript wo means without the MO provision, and $w$ means with the MO provision. It follows that $K>a e^{g T} / b$, so the investor chooses $K^{w}, T^{w}$ to maximise

$$
\pi(K, T)=\int_{T}^{\infty}\left((a-\beta) K-b e^{-g t} K^{2}-F\right) e^{-r t} d t .
$$

The Appendix shows that the profit-maximising choices of $K^{w}$ and $T^{w}$ are:

$$
K^{w}=\left(\frac{2 r}{r-g}\right) \frac{F}{a-\beta},
$$

and

$$
e^{g T^{w}}=\frac{4 b r^{2} F}{\left(r^{2}-g^{2}\right)(a-\beta)^{2}},
$$

provided that $F$ is sufficiently large for this to exceed 1 (otherwise investment takes place immediately and should have already occurred). In what follows we assume that $F$ is sufficiently large that it is socially optimal to delay investment, so that we are looking at an interesting ex ante choice problem, rather than regretting failures to invest in the past.

\section{Socially optimal investment}

Whereas a merchant investor would never invest in enough capacity to drive the price to zero, a regulated investor charged to maximise social welfare might find the consumer surplus at zero price sufficiently high to justify such a choice of capacity. There are thus two cases to consider, depending on whether it is optimal to invest early and enjoy a period of spare capacity and zero price, or whether the interconnector will be delayed until it is fully used. The second case is particularly simple to solve as the social maximand differs from the merchant choice under MO solely by replacing $b$ in (14) by $b / 2$. It then follows immediately that the socially optimal choices of $K^{*}, T^{*}$ (where * indicates the socially optimal choice) is 


$$
K^{*}=\left(\frac{2 r}{r-g}\right) \frac{F}{a-\beta}=K^{w},
$$

and

$$
e^{g T^{*}}=\frac{2 b r^{2} F}{\left(r^{2}-g^{2}\right)(a-\beta)^{2}}=\frac{1}{2} e^{g T^{w}} .
$$

It follows that $T^{*}<T^{w}$. We note that in this case the merchant investor chooses the efficient level of capacity but delays until demand is twice as high as at the socially optimal date.

If, on the other hand, it is desirable to invest earlier, the social maximand is

$$
W(K, T)=\int_{T}^{\infty}\left(a Q(t)-\frac{1}{2} b e^{-g t} Q(t)^{2}-\beta K-F\right) e^{-r t} d t, \quad Q(t) \leq K .
$$

Line usage $Q(t)$ when $Q(t)<K$ is set to drive the price to zero:

$$
Q(t)=\frac{a e^{g t}}{b}, t<M, Q(M)=K=\frac{a e^{g M}}{b} .
$$

This is solved for the socially optimal values $K^{* *}$ and $T^{* *}$ :

$$
e^{g T^{* *}}=\frac{2 b F}{a(a-2 \beta \theta)},
$$

where

$$
\theta=\left(\frac{a g}{\beta(r+g)}\right)^{g / r}
$$

and

$$
K * *=\frac{2 F \theta}{a-2 \beta \theta}
$$

The second case of under-used capacity holds provided $M>T$, or (as the Appendix shows) if $\theta>1$, which is equivalent to $\beta<a g /(r+g)$. Thus early investment with under-used capacity is socially optimal if the LRMC of expanding the interconnector is low (relative to the price) and the discount rate is low (relative to the rate of growth).

\section{Merchant investment without MO}

The next question is whether removing the MO provision improves matters for market investment. This seems intuitively likely, given that MO could result in an earlier date of investment, although it is not immediately clear what effect (if any) it has on the choice of $K$. Again there is a direct read-across from the socially optimal choice allowing for a period of under-utilised capacity and the merchant maximand, by replacing the $b / 2$ in (19) by $b$ to give 


$$
e^{g T^{w o}}=\frac{4 b F}{a(a-2 \beta \theta)}=2 e^{g T^{* *}},
$$

and

$$
K^{w o}=\frac{2 F \theta}{a-2 \beta \theta}=K^{* *} .
$$

It follows that $T^{w o}>T^{* *}$. Note as above that while the welfare maximiser invests earlier than the merchant, the capacity choices of the merchant and welfare maximiser are the same. ${ }^{12}$ This rather surprising result appears to contradict the textbook static case where the monopoly outcome is half the welfare maximising outcome and needs some clarifying words.

The process above only holds for $\theta>1$. This requires in particular that demand growth $g$ is sufficiently large. If this condition is fulfilled then $K^{* *}=K^{w o}$ and (or rather because) $T^{w o}>$ $T^{* *}$. Demand growth creates the option to wait. If by static comparison, $g$ decreases two things happen: the investment moment $T$ decreases and the capacity $K$ decreases in both cases. At the moment that the optimal investment moment is now (i.e. $T=0$ ), the process stops, as negative time is clearly not allowed. At parameter values such that $T^{* *}=0$, investment time of merchant is still positive $T^{w o}>0$. If parameters are changed further, nothing changes anymore in the welfare-optimising case, ${ }^{13}$ while both $T^{w o}$ and $K^{w o}$ are still reduced. And thus $K^{* *}>K^{w o}$. This continues until also $T^{w o}=0$. At that moment, $K^{* *}=a / b$ for the welfare case and $K^{w o}=a / 2 b$ for the profit-maximising case. Hence, we see that if $g$ decreases (and drops below a critical value for which $\theta<1$ ), the capacities diverge from each other and instead converge to the static textbook case.

The next step is to rank the outcomes with and without the MO provision. We proceed in steps.

Proposition 2A: MO is irrelevant if $\beta>a g /(r+g)$.

Proof: The value of $M$ that solves $e^{g M}=b K / a$ has $M<T$ for $\theta<1$, and in that case it will be profitable to fully use the capacity at the date of investment. The Appendix shows the condition $\theta<1$ is equivalent to $\beta>a g /(r+g)$.

An MO provision thus only has an effect if $\theta>1$. Given its crucial importance, $\theta$ deserves somewhat more attention. Examination of $g$ reveals that $\theta$ goes to 1 for $g$ approaching zero, decreases if $g$ increases from zero, reaches a minimum and then increases monotonically. Hence $\theta>1$ for some $g>g^{*}$. $\theta$ and $g^{*}$ are critically determined by $\beta ; \theta$ falls with increasing $\beta$. In words, an MO provision loses relevance if the growth rate is small and capacity expansion costs are high. The MO provision only has meaning if the investor would withhold capacity. If $\beta$

\footnotetext{
12 The equality depends rather critically on the specification of demand (growth), in particular the fact that ' $a$ ' does not change.

${ }^{13}$ Technically speaking, the outcome where the capacity with withholding is smaller than the minimum capacity as defined above, occurs only for $T<0$ which of course should be excluded.
} 
is high, early oversized investment with capacity withholding for some time is expensive. What happens endogenously in the solutions is that as $\beta$ increases (and thus $\theta$ decreases), both $T$ and $M$ increase while ( $T$ - $M$ ) decreases (and $K$ increases). At exactly $\theta=1, T=M$, and for $\theta\langle 1, T\rangle$ $M$. This says that as $\beta$ increases, the strategy of capacity withholding loses relevance until it vanishes altogether $(T=M)$. Note that if $T>M$ (and thus $\theta<1)$ the constraint $Q \leq K$ binds.

Proposition 2B: When the MO provision has an effect, it decreases capacity. That is, if $\theta>1$, $K^{w o}>K^{w}$.

Proof: We need to establish the inequality in

$$
K^{w}=\left(\frac{2 r}{r-g}\right)\left(\frac{F}{a-\beta}\right)<\frac{2 F \theta}{a-2 \beta \theta}=K^{w o}, \text { for } \theta>1 .
$$

First note that using (15), (17), (23) and (25) that at $\theta=1, K^{w}=\left.K^{*}\right|_{\theta \leq 1}=\left.K^{* *}\right|_{\theta \geq 1}=K^{w o} . K^{w}$ is increasing in $\beta$ and therefore decreasing in $\theta$, while $K^{w o}$ is increasing in $\theta$. QED.

Proposition 2C: When the MO provision has an effect, it delays investment. That is, for $\theta>$ $1, T^{w o}<T^{w}$.

Proof: Again note from (16) and (24) that $T^{w o}=T^{w}$ at $\theta=1$. By differentiation, $T^{w}-T^{w o}$ is decreasing in $\beta$ and therefore increasing in $\theta$ at $\theta \geq 1$. QED.

Conjecture: $S W^{w o}>S W^{w}$, for $\theta>1$. Since $S W^{w o}=S W^{w}$, for $\theta \leq 1$, the implication is that an MO provision weakly decreases social welfare.

Numerical analysis confirms the conjecture over a wide range of parameter values. The analytical intuition for its plausibility is as follows. Consider figure 1.

without MO

with MO

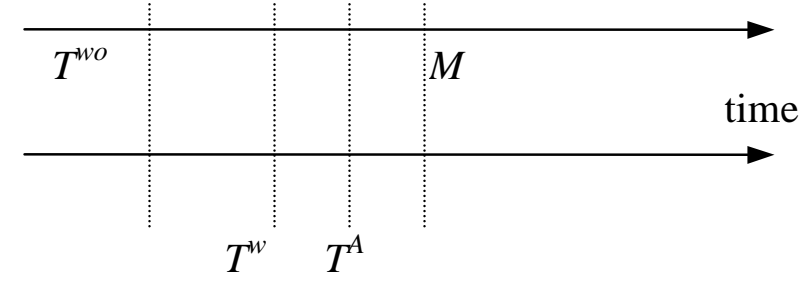

\section{Figure 1: Time line for $\theta>1$}

With $\theta=1, T^{w o}=M=T^{w}, Q^{w o}=K^{w o}=K^{w}$, and (thus) $S W^{w o}=S W^{w}$. Outcomes in timing, capacity and output start to diverge if $\theta>1$. A first effect is that $K^{w o}>K^{w}$, implying that if production is at full capacity, the welfare effect of the MO is negative. A second effect is that $\left(M-T^{w o}\right)$ increases, implying a longer period with $Q^{w o}<K^{w o}$. This effect consists of two opposing effects. First, $\left(T^{w}-T^{w o}\right)$ increases, meaning that for a longer period there will be 
investment (and output) without an MO provision and none with. During this period an MO provision decreases welfare. Second, $M-T^{w}$ increases, which implies a longer period where $Q^{w o}<Q^{w}=K^{w}<K^{w o}$, which is positive for an MO provision. Since at $M, Q^{w o}=K^{w o}>K^{w}$, there must a point $T^{A}<M$ at which $S W^{w o}=S W^{w}$ (and larger beyond that $T^{A}$ ). The numerical computations suggest that the positive effect of an MO provision (between $T^{w}$ and $T^{A}$ ) is more than offset by the welfare reducing effects outside this range.

Clearly, this analysis is incomplete, as one might wish to consider a sequence of investments in a growing market (or otherwise consider why the interconnector market may cease to grow) and one may also wish to consider competition between potential investors, as an investment race. The first case is unlikely to add anything but complexity. We have not formally examined the investment race for two reasons. First, empirically, racing to build high voltage interconnectors does not seem very relevant. The question is whether there will be a potential investor at all. Thus in the case of BritNed it seems that the only candidates are the TSOs on both sides who formed a joint venture. To the knowledge of the authors, there are no other candidates. Second, the main focus of investment races is on the dissemination of benefits; particularly where competition on the downstream market is less than perfect. ${ }^{14}$ We briefly discuss imperfect downstream competition in section 3, but leave the case of growing demand and possible investment races to further research.

For the case of a large number of potential investors and perfect downstream competition, which implies zero excess profits, the following informal observations can be made. Denote subscript " $R$ " for the racing scenario. Because the investor without an MO provision can always mimic the outcome under an MO provision it follows that $\pi^{w o} \geq \pi^{w}$, and thus $T_{R}^{w o} \leq T_{R}^{w}$. Thus the following must hold:

$$
\int_{T_{R}^{w o}}^{\infty} \pi^{w o} e^{-r t} d t \geq \int_{T_{R}^{m o}}^{\infty} \pi^{w} e^{-r t} d t
$$

Here, $\pi$ is defined net of investment cost. Perfectly competitive racing implies that the net present value of cash flow must be just equal to the discounted investment cost, and thus $C\left(K_{R}^{w o}\right) e^{-r T^{w o}} \geq C\left(K_{R}^{w}\right) e^{-r T^{w}}$, and thus if the investment cost are increasing in $K$, we can draw no immediate conclusions for capacity. However, we observe that the investor not subject to an MO provision can only increase profits (compared to the MO provision) by making larger profits in the later periods of higher demand, which requires larger capacity. Hence we may conclude that racing will speed up the investment as compared to no racing, but that the results with respect to the MO provision do not change.

\footnotetext{
${ }^{14}$ Seminal in the context of innovation is Katz \& Shapiro [1987], which builds upon Dasgupta \& Stiglitz [1980] and Gilbert \& Newbery [1982]. Applied specifically to the network access question is Gans \& King [2004]. However, these do not examine a must-offer provision that is the main focus of this paper. Moreover, this literature does not endogenize the size of capacity, but focuses on timing only.
} 


\subsection{Pre-emptive investment}

Pre-emptive investment (i.e. the choice of interconnector capacity and/or timing with the intention of deterring subsequent interconnector investment) may well be plausible. Planned and realised examples in Australia, the US and Europe suggest that interconnector markets can be quite large and that quite small lines may be viable. Subsequent entry is a reasonable option and thus pre-emptive investment may be a plausible strategy.

This section examines the effects of an MO provision in the face of potentially preemptive investment. The mechanism is slightly different from the mechanism in the sections above. Following the seminal approach of Dixit [1980], entry deterrence is made more effective if the first mover can credibly commit to fully use his capacity post-entry, to the disadvantage of the entrant. Entry deterrence without an MO provision is only credible if the post-entry profit-maximising output, based on marginal cost net of sunk investment, leaves the entrant's profit just negative. A larger post-entry output is not credible even if faced with excess capacity. Where entry deterrence is not or no longer credible, an explicit MO provision will have the effect to make the entry deterrent capacity credible and may therefore enhance the ability to deter entry. Although somewhat surprisingly, this may enhance welfare. As for example von Weiszäcker [1980] pointed out, entry barriers might have beneficial effects if in the post-entry market both players adopted Cournot strategies that would induce excessive entry. The same reasoning underlies the welfare effects here. The MO provision works as an entry barrier that can have both positive and negative welfare effects. There may be a (narrow) range of values of fixed and variable capacity values that make an MO provision welfare decreasing, but as fixed costs become less important, the value of the MO provision in deterring multiple duplicative entry increases, enhancing social welfare.

This has some similarity to the finding of Eaton and Ware [1987], who consider a normal market with sequential market entry. They find that "strategic entry deterrence is ordinarily welfare improving" although they only allow the incumbent to deter entry by strategic investment, not by an MO provision. In our setting giving the firm additional power to deter entry by imposing an MO provision when otherwise multiple entry would occur is welfare improving.

The setting is as follows: firm 1 is the merchant investor who considers strategic preemption; firm 2 is the (first) potential entrant who contemplates building a parallel interconnector. The game is sequential in three stages. In stage 1 firm 1 invests in the line and decides (irreversibly) on the capacity. At stage 2 firm 2 decides whether or not to invest in a line, after observing the sunk capacity of the first firm. In the final stage 3 trading establishes the price in the energy markets given the capacity of the line(s). We assume that if entry occurs, there is a well-defined order in which possible entrants take decisions, that there is no uncertainty about future demand, and that the form of competition post entry depends on whether or not there is a MO provision. Under MO the first investor will offer full capacity, and any potential entrant anticipates this when choosing capacity. Without the MO provision, the incumbent can choose to reduce output if this would increase profits, given subsequent entrants' capacity choices (which will in equilibrium be fully used). For the most part we 
only need to consider cases where there is room for at most two entrants. If entry cannot be deterred and fixed costs are low enough, a whole sequence of firms will enter, causing excessive fixed cost duplication. Eaton and Ware (1987] show how to solve for the multiple entry case, which does not change our welfare results.

If the first investor predicts that entry will occur, he will choose a smaller capacity to ensure that in the post-entry game he has no idle capacity. The capacity choice can therefore be modelled as a Stackelberg game. As before, residual demand for interconnector capacity is linear, so $p=a-b\left(Q_{1}+Q_{2}\right)$, as is the cost function for (constructing) the line:

$$
C_{i}\left(K_{i}\right)=F+\beta \cdot K_{i}, \text { for firms } i=1,2 .
$$

The question to be addressed is whether social welfare with an MO provision $\left(S W^{W}\right)$ is larger or smaller than social welfare without an MO provision.

Consider figure 2, which outlines the strategies against the level of the fixed costs (the equations are derived below).

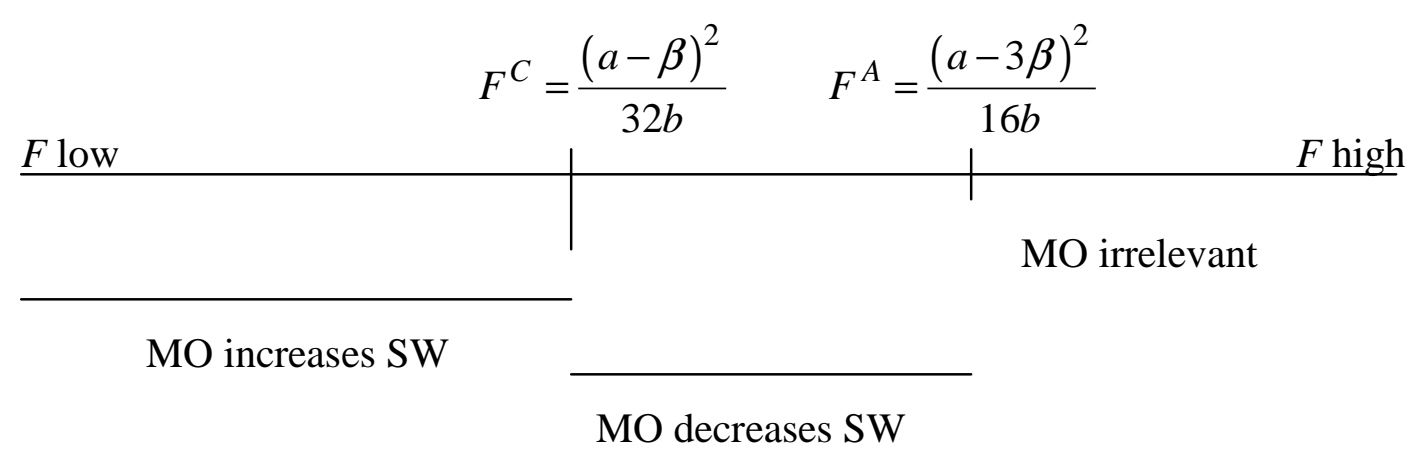

\section{Figure 2: Overview of pre-emptive investment}

If $F$ is large, entry will not be profitable even without an MO provision. In that case the first mover simply invests in the monopoly capacity and produces accordingly and blockades entry as a by-effect. Thus an MO provision would have no effect. If $F$ is below $F^{C}$, it is always profitable to deter entry (and avoid duplicating fixed costs) provided this is possible, which requires an MO, otherwise inefficient entry will occur lowering social welfare. To the right of point $F^{A}$, strategic entry deterrence is profitable exploiting the asymmetry in sunk costs and an MO is not needed to deter entry.

The policy relevant range is thus below $F^{A} . F^{A}$ determines where fixed costs $F$ are sufficiently low such that entry deterrence based on asymmetry of sunk costs is not profitable and thus entry deterring investment is not credible without an MO. Below $F^{A}$, an MO provision makes a difference and therefore will have an effect on social welfare. Proposition 4 below shows that between $F^{C}$ and $F^{A}$ a MO provision has adverse effects, but below $F^{C}$ it is beneficial.

To establish these claims, the Stackelberg game must be solved backwards. If the entrant chooses to enter, he will choose output $Q_{2}=K_{2}$ to maximise: 


$$
\pi_{2}^{s}=P\left(Q_{1}, Q_{2}\right) \cdot Q_{2}-\beta \cdot Q_{2}-F
$$

The first-order condition gives the reaction function:

$$
Q_{2}^{s}=\frac{a-\beta-b Q_{1}^{c}}{2 b}
$$

Without an MO provision firm 1 cannot commit to an ex post unprofitable level of output. In the case of blockaded entry, the choice of the first mover's capacity ignoring the threat of entry will be sufficient to make subsequent entry unprofitable. In that case the monopoly solution is:

$$
Q_{1}=K_{1}^{m}=\frac{a-\beta}{2 b},
$$

so that if another investor entered he would choose output:

$$
Q_{2}=\frac{a-\beta}{4 b} .
$$

The first mover's preferred level of capacity and output will blockade entry without an MO provision if the entrant's profits would be negative at this choice of output, $Q_{1}$, which requires $F>(a-\beta)^{2} / 16 b$. The first mover may still be able to deter output by selecting a level of capacity very slightly higher than the ex post profit maximising level of output given entry, for in this case his marginal cost will be zero, not $\beta$, and hence his profit maximising choice of output, $Q_{1}$, will maximise (using 2's reaction function, $Q_{2}^{S}$ ):

$$
\pi_{1}^{s}=p \cdot Q_{1}-\beta K_{1}-F=\frac{1}{2}\left(a+\beta-b Q_{1}\right) Q_{1}-\beta K_{1}-F
$$

This gives:

$$
Q_{1}=K_{1}^{S}=\frac{a+\beta}{2 b}, Q_{2}=\frac{a-3 \beta}{4 b} .
$$

With an MO provision, firm 1 will choose $Q_{1}=K_{1}$ to deter entry by making the output choice of the potential entrant, given $K_{1}$, unprofitable; $\pi_{2}^{s} \leq 0$ for $Q_{2}^{s}$. This requires $K_{1} \geq K^{L}$, the limit capacity:

$$
K^{L}=\frac{a-\beta}{b}-\gamma, \text { with } \gamma=\frac{\sqrt{4 b F}}{b}=\sqrt{\frac{4 F}{b}} .
$$

The pre-emptive capacity is equal to the competitive output minus a positive fraction which depends on $b$ and fixed costs $F$. In line with standard theory on limit pricing, the limit capacity decreases if demand gets more elastic (i.e. $b$ is small) and if fixed costs increase ceteris paribus. $^{15}$

\footnotetext{
${ }^{15} \mathrm{Cf}$. for instance Gilbert [1989] for an overview.
} 
The first mover will be able to deter entry without an MO provision if the entrant's profits would be negative at this choice of output, $Q_{1}$, otherwise entry would be accommodated. Equalising $K_{1}^{S}$ from (34) and $K^{L}$ from (35) and solving for $F$ gives the lowest level of fixed costs for which entry is deterred without an MO provision: $F=(a-3 \beta)^{2} / 16 b$. This in turn gives

Proposition 3: If $F<(a-3 \beta)^{2} / 16 b$, the MO provision induces entry-deterring behaviour whereas without an MO provision entry deterrence would not be profitable.

Denote $S W^{w}$ as social welfare with an MO provision (entry deterrence), and $S W^{a c}$ as social welfare in the Stackelberg duopoly (entry accommodation). The entry-deterrent MO provision increases welfare if:

$$
S W^{w}=\int_{0}^{Q^{w}} p(Q) d Q-\beta \cdot Q^{w}-F>\int_{0}^{Q^{a c}} p(Q) d Q-\beta \cdot Q^{a c}-2 F=S W^{a c}
$$

The values for the limits can be determined as $Q^{w}=K^{L}$ and $Q^{a c}=3(a-\beta) / 4 b$, and the integrals evaluated to give the following proposition:

Proposition 4: If $F<\frac{(a-\beta)^{2}}{32 b}$, the MO provision increases welfare, whereas for $\frac{(a-\beta)^{2}}{32 b}<F<\frac{(a-3 \beta)^{2}}{16 b}$, the MO provision decreases welfare.

The second condition is only non-empty if

$$
\frac{(a-\beta)^{2}}{32 b}<\frac{(a-3 \beta)^{2}}{16 b},
$$

This condition is only satisfied for $x=\beta / a<0.1277$, or $\beta / a>0.4605$, the two roots of the quadratic equation $17 x^{2}-10 x+1>0$, and for values between these roots, the MO provision either does not have an effect or is welfare increasing (depending on the size of $F$ ). If $\beta$ is very low, the costs of entry deterrence are low while at the same time entry deterrence requires relatively large capacity as a result of which the additional competition from the entrant has a relatively small effect. On balance, the MO provision is more likely to increase social welfare with low $\beta$. If $\beta$ is high, entry deterrence in the absence of an MO provision is more credible, which increases the range in which an MO provision is irrelevant: in figure 2, $F^{A}$ shifts to the left.

\section{MARKET POWER WITHIN THE IMPORTING COUNTRY}

The analysis so far ignores any independent strategic behaviour on the part of domestic generators, and concentrates on the potential for the interconnector owner to influence market 
prices. This is reasonable if there is a domestic incumbent who also controls access to the interconnector, and faces a residual demand (from a fringe of competitive generators and consumer demand). However, these are exactly the circumstances in which a regulator or competition authority would wish to limit the incumbent's access to the interconnector, both by prohibition on dominant ownership of the interconnector (and/or its capacity) and by suitable interconnector auction design (Gilbert, Neuhoff and Newbery, 2004).

If dominant domestic generators are prevented both from owning and holding capacity on the interconnector, then there is a potential interaction between the market power of incumbents and of the agent controlling the size and use of the interconnector. This becomes important for any welfare analysis of alternative regimes, as domestic prices no longer properly measure marginal social costs and benefits.

The simplest case to analyse has competitive prices in the exporting country, at level $m$ (independent of interconnector volumes, $Q$, at any date, but possibly varying from period to period, as with Norwegian electricity, where Norwegian prices depend on hydro conditions). Within the importing country there are $n$ domestic incumbents each with constant marginal cost $c$, each producing $q$, and selling at domestic price $p$. Total relevant supply is $n q+Q$, where as before, the inverse demand schedule is $p=a-b(n q+Q)$.

A merchant interconnector would be built and operated by a company with no generation assets, while a regulated interconnector would be jointly financed by each country, and the trading profits divided in proportion to ownership (assumed equal). In the static case, demand is known and on average constant (though it may vary over a number of possible states of the world) and the exporting country's price is similarly constant on average even if it differs in each state. As before, the merchant investor chooses capacity, $K$, with and without an MO provision, which will be ranked in terms of the social welfare of the importing country, and compared to a (possibly more expensive) efficiently priced regulated interconnector under shared ownership. If the interconnector capacity is adequate, the price differential $\left(p_{m}-p_{x}\right)$ between the countries will be equal to the line's capacity expansion costs $\beta$.

\subsection{Deterministic demand in both countries}

The main question is how the market equilibrates and with what impact on social welfare, compared to a more expensive regulated interconnector. (The higher cost, $F^{*}+\beta^{*} K$, may reflect the slower process in deciding on the interconnector, or the inefficiencies of regulation rather than private ownership, or both.)

As with the case of pre-emption, the investor in the interconnector has a first-mover advantage, and must decide whether to invest with the intention of aggressively discouraging incumbent output, or whether to accommodate. The difference here is that the incumbents have already sunk their investment costs and will choose to operate in any case, while the marginal cost of interconnector investment exceeds that of operation, discouraging over-investment and making the MO provision irrelevant. The equilibrium is found by first identifying the incumbent reaction function. Each incumbent chooses output $q$ given imports over the interconnector, $Q$, so that its equilibrium output will be 


$$
q=\frac{(a-c-b Q)}{(n+1) b}
$$

and the market clearing price will be

$$
p=\frac{a+n c-b Q}{n+1}
$$

(The initial equilibrium can be found by setting $Q=0$.) Consider the choice of interconnector capacity assuming that $K=Q$ in equations (39) and (40). Interconnector profits will be

$$
\pi=K(p-m)-F-\beta K=\left(\frac{a+n c-b K}{n+1}-m-\beta\right) K-F .
$$

The profit maximising choice of $K$ will be

$$
K^{\max }=\frac{a+n c-(n+1)(m+\beta)}{2 b} \equiv \frac{a+n c-B}{2 b},
$$

where $B \equiv(n+1)(m+\beta)$. The interconnector would be fully used ex post if the Nash-Cournot output ignoring the investment cost is at least as great as capacity, which it must be, as the ex ante marginal cost of investment is greater than the ex post marginal cost of use. The price will be

$$
p=\frac{a+n c+B}{2(n+1)}
$$

Profits, which have to be non-negative after covering the fixed cost $F$, are

$$
\pi=K(p-m-\beta)-F=\frac{(a+n c-B)^{2}}{4(n+1) b}-F>0 .
$$

This requires

$$
a+n c-B>\sqrt{4(n+1) b F},
$$

and so $p>m+\beta$, the relevant marginal cost of importing.

\section{Impact of the interconnector on social welfare}

In the absence of an interconnector social welfare (defined as the sum of producer and consumer surplus) is $n(n+2)(a-c)^{2} /\left(2(n+1)^{2} b\right)$. If the interconnector is built the importing country's social welfare will be the resident share of the merchant profit plus domestic producer and consumer surplus: 


$$
\begin{aligned}
& W=\frac{1}{2} \pi+\frac{1}{2}(a-p)(K+n q)+(p-c) n q= \\
& \frac{(n+1)(p-m-\beta)^{2}}{2 b}+\frac{(a-p)^{2}}{2 b}+\frac{(p-c)^{2}}{b}-\frac{1}{2} F .
\end{aligned}
$$

The interconnector clearly increases social welfare if marginal import costs are less than marginal domestic costs, i.e. if $c>m+\beta$, but that is not guaranteed by the private profitability of the interconnector, (43). The change in welfare resulting from the interconnector is given by the equation

$$
\Delta W=\frac{-(4 n-3) a^{2}+\left(6 n^{2}+12 n-8\right) a c+\left(n^{3}+8\right) c^{2}+(n+4) B^{2}-2 B\left(3 n a+\left(n^{2}+2 n+4\right) c\right)}{8 b(n+1)^{2}}-\frac{1}{2} F
$$

Proposition 5: For $c>c^{*}$, social welfare is increased by allowing the construction of a merchant interconnnector, and reduced for $c<c^{*}$, where $c^{*}<m+\beta$.

The proof is the Appendix. The proposition is unsurprising, for the extra competition from a merchant interconnector reduces the deadweight loss from inefficient domestic competition and so it may be desirable to import at a (long-run) marginal cost (including fixed costs) above the marginal domestic production cost. It also follows that merchants may profitably invest (exploiting the wedge between price and production costs on the energy market) while the investment is welfare decreasing. This suggests that it may be a need to have a regulatory test before approving the merchant interconnector, and a sufficient condition is $m+\beta<c$.

\section{Regulated interconnector}

If the interconnector is built as a regulated line, we can ask what value of $K$ maximises $W$ for the importing country. By regulated we mean here that building the line needs the regulator's approval and more importantly, that the regulator directly or indirectly determines the line's capacity. A regulated interconnector may have higher costs than a merchant line, but if $\beta^{*}+m<$ $c$ it could be cheaper to import all domestic demand and eliminate local production. On the other hand if $\beta^{*}+m>c>m$ the only merit of the interconnector is as a rather expensive way of mitigating domestic market power. If domestic marginal costs were increasing, then some level of imports might be desirable, and the problem might then be better posed. We consider this alternative below.

If we nevertheless stay with the linear model, and consider social welfare from the importing country's perspective, assuming that it finances the interconnector and thus receives all the net profit of the interconnector. This is in contrast to the merchant case above where the profits were shared between the two countries. To this must be added domestic consumer and producer surplus to give the total social benefits, $W$ :

$$
W=\frac{1}{2}(a-p)(K+n q)+\pi_{I}+n \pi_{G}
$$

Using $q$ and $p$ from (38) and (39) respectively, the FOC w.r.t. $K$ is: 


$$
\frac{\partial W}{\partial K}=\frac{a+n(n+2) c-b K^{*}}{(n+1)^{2}}-\left(m+\beta^{*}\right)=0 .
$$

The optimal capacity is:

$$
K^{*}=\frac{a-c+(n+1)^{2}\left(c-m-\beta^{*}\right)}{b} .
$$

Optimal capacity $K^{*}$ decreases with larger $n$ and $\left(m+\beta^{*}\right)$. The trade-off involved here is the effect of higher competition on the home market, which requires a large capacity, versus the import of expensive power, which reduces optimal capacity. It is clear that if $\left(m+\beta^{*}\right)<c$ the interconnector capacity should be equal to the entire size of the market. The case of interest is where $\left(m+\beta^{*}\right)>c$.

Interestingly, it is ambiguous whether the welfare maximising capacity $\left(K^{*}\right)$ is larger or smaller than the profit maximising $K^{\max }$ from (41). Comparison reveals that $K^{\max }<K^{*}$, if:

$$
a+\left(2 n^{2}+3 n\right) c>\left(2 n^{2}+3 n+1\right)(m+\beta *) .
$$

If $n$ is large (competitive home production market) and $\left(m+\beta^{*}\right)>c$, the LHS $<$ RHS and thus $K^{\max }>K^{*}$. With a competitive home market and expensive imports, society does not gain from the interconnector and wants the line to be small. As has been pointed out by Joskow \& Tirole (2005), in these circumstances, a merchant line will be too large rather than too small. Logically, as the line does not pass the regulatory test it should not be built as a merchant line, and there should be better ways of addressing local market power. On the other hand, assuming $n=1$ and solving the condition gives:

$$
(m+\beta *)<\frac{a+5 c}{6}
$$

Thus if $n$ is low and $m+\beta^{*}$ not too high, $K^{\max }<K^{*}$ and conversely.

\section{Extensions to tender auctions for merchant interconnectors}

Under circumstances where merchant interconnectors will be typically under-sized, a regulator concerned with maximising social benefits might organise an auction to determine the size of the interconnector. A natural choice of auction design is to accept the merchant proposal with the largest capacity, which again raises the question whether such an interconnector should be subject to an MO provision or not. In this case the MO provision has opposing effects and the choice is not unambiguous. In general, however, the MO provision is more likely to be welfare enhancing than in the case of unregulated MTI.

It is clear that waiving the MO provision will lead to a (weakly) larger interconnector, as the profits for any given size of interconnector are (weakly) higher without MO for each given size than with MO. In a competitive tender the higher profits will be bid away; by auction design the winning bid is the highest capacity possible with non-negative profits. This results in overinvestment and increases the incentives for capacity withholding. As the MO decreases the (ex post) profits, the winning bid has lower capacity and thus lowers the extent of over-investment. 
In the reference case, the MO provision enhances welfare in case of a competitive tender. As shown in section 2, the MO provision weakly decreases welfare under demand uncertainty and demand growth, establishing opposing effects. With an organised tender, pre-emptive investment to hold off a second investor will not be an issue.

\section{Extension to increasing marginal cost}

A more general, although somewhat more complex analysis, might consider increasing domestic costs, making the social case for imports less critically dependent on the condition $\beta^{*}+m>c>$ $m$. If there is a single dominant incumbent whose cost function is $C(q)=c q+1 / 2 \gamma q^{2}$, marginal cost will be $c+\gamma q$ and the incumbent's reaction function will be

$$
q=\frac{(a-c-b Q)}{2 b+\gamma}
$$

It is then possible to repeat the previous analysis and to find a wider range of conditions under which an interconnector is socially beneficial.

\subsection{Uncertain import costs}

Again applying a MO provision, we now turn to uncertainty in the cost of imports; the analysis is similar to demand uncertainty as in section 2.1 , but here the interconnector faces an import energy market and thus residual demand. The more normal case is that the interconnector takes advantage of varying price differences between countries, which can be represented by variability in the price of imports, so that $m$ becomes a random variable taking different values $m_{s}$ in different states of the world $s$. Let $\alpha_{s}$ be the probability of state $s$, with $\Sigma \alpha_{s}=1$, with the expected value $\mathrm{E} m_{s}=\Sigma \alpha_{s} m_{s}=m$. Incumbent domestic generators maximise profits conditional upon the interconnector output. If there is no MO provision, then the interconnector maximizes expected profits as a Stackelberg leader given the reaction functions of (38):

$$
\max _{Q_{s}, K} \pi_{I}=\sum_{s} \alpha_{s}\left(p_{s}-m_{s}\right) Q_{s}-\beta K-F_{I}-\sum_{s} \lambda_{s}\left(Q_{s}-K\right)
$$

with $p_{s}$ given by (39) for $Q=Q_{s}$. The first order conditions (FOCs) are:

$$
\begin{gathered}
\frac{\partial \pi_{I}}{\partial Q_{s}}=\alpha_{s}\left[\frac{a+n c-2 b Q_{s}}{n+1}-m_{s}\right]-\lambda_{s}=0, \text { for all s } \\
\frac{\partial \pi_{I}}{\partial K}=-\beta+\sum_{s} \lambda_{s}=0 .
\end{gathered}
$$

In the simple case there are two states, a low import price state $s=L$ and a high price state $H$ : $m_{L}<m_{H}$. If $m_{H}<m_{L}+\beta / \alpha_{L}$, capacity will not be withheld even if there is no MO provision as there is a positive shadow price on capacity in both states, $\lambda_{H}, \lambda_{L}>0$, so that $Q_{L}=Q_{H}=K$. If $m_{H}>m_{L}+\beta / \alpha_{L}$, it is attractive to withhold capacity if legal: $\lambda_{H}=0$ and $\lambda_{L}=\beta$. 


\section{No capacity withholding}

If $m_{H}<m_{L}+\beta / \alpha_{L}$ then $Q_{L}=Q_{H}=K$. Solving the FOCs for these assumptions then gives the same result as in the deterministic case (41):

$$
K^{N}=\frac{a+n c-(n+1)(m+\beta)}{2 b}=\frac{a+n c-B}{2 b}, \text { where } m=\operatorname{E} m_{s} B=(n+1)(m+\beta)
$$

\section{Capacity withholding}

Now suppose that $m_{H}>m_{L}+\beta / \alpha_{L}$, then $\lambda_{H}=0, \lambda_{L}=\beta$. Solving the FOCs using these assumptions:

$$
Q_{H}^{w}=\frac{a+n c-(n+1) m_{H}}{2 b}
$$

and

$$
Q_{L}^{w}=K^{w}=\frac{a+n c-(n+1)\left(m_{L}+\beta / \alpha_{L}\right)}{2 b} .
$$

It is evident that $m_{H}>m_{L}+\beta / \alpha_{L}$ is the condition for $Q_{H}^{w}<K^{w}$. As in section 2.1, if there is an MO provision that has an effect, (i.e. if $m_{H}>m_{L}+\beta / \alpha_{L}$ ) then the MO provision results in less investment. That is, $K^{M O}<K^{w}$, for then $K^{M O}=K^{N}$ as in (56), and $m_{L}+\beta / \alpha_{L}<m+\beta$, because then $m+\beta=\left(1-\alpha_{L}\right) m_{H}+\alpha_{L} m_{L}+\beta=\left(1-\alpha_{L}\right)\left(m_{L}+\beta / \alpha_{L}+\varepsilon\right)+\alpha_{L} m_{L}+\beta$ for some $\varepsilon$ $>0$.

Define the expected value of a variable $x$ : $\mathrm{E} x=\alpha_{H} x_{H}+\alpha_{L} x_{L}$. Then we have

Lemma 1: The expected price and output are the same with or without $\mathrm{MO}$ or $\mathrm{E}(Q+n q)=$ $(Q+n q)^{N}$ and $\mathrm{E} p=p^{N}$.

Proof: From (57) plus (58) and (56), EQ $=Q^{N}$. Using (38) and substituting $Q_{L}^{w}, Q_{H}^{w}, E Q$ gives: $\mathrm{E} q=q^{N}$. It follows that $\mathrm{E}(Q+n q)=(Q+n q)^{N}$ and $\mathrm{E} p=p^{N}$.

Proposition 6: An MO provision weakly decreases welfare under import cost uncertainty.

The proof is in the Appendix.

\section{CONCLUDING REMARKS}

Unregulated merchant transmission investment (MTI) means that the sole source of revenue for the investment comes from trading between the markets the line interconnects, rather than being supplemented from the pool of regulated connection charges. Moreover, the investment can be undertaken by new, possibly more entrepreneurial companies than the designated transmission system operators (TSOs). TSOs are charged to deliver a secure and economical transmission service to their domestic clients, and may overlook commercial activities such as investing in interconnectors. If they do and ask for them to be treated as regulated 
investments, then domestic regulators may be sceptical of their true social benefit. The resulting stalemate risks serious underinvestment in network assets, and is appears to be a powerful driver for merchant investment. The paper focuses on the European institutional framework as opposed to the USA and thereby on direct-current interconnectors linking different countries (or regions under different TSOs). An interesting topical case is a planned interconnector between the UK and the Netherlands, called BritNed.

Merchant interconnectors raise a set of regulatory questions, one which is whether or not to apply a must-offer (MO) provision. The legislative context for MTI in Europe has been laid down in the EU Regulation on Cross-border Exchanges which entered into force in July 2004. The Regulation as currently formulated includes an MO provision although this may not have been consciously intended for new interconnectors,. Such provisions are not uncommon and quite uncontroversial for existing assets (both generation and interconnectors), but raise questions for new interconnectors where the investment decision still has to be made. The basic trade-off is that an MO provision, obliging the line owner to offer all capacity into the market, increases short-term welfare, but at the expense of reduced capacity and thus lower long-term welfare. This paper identifies circumstances in which the balance is in favour or against an MO provision.

An MO provision tackles (strategic) capacity withholding. Given that the capacity decision still has to be made and given that revenues are unregulated it is not immediately obvious why capacity withholding would be a profitable strategy. We examined three cases: demand uncertainty, demand growth and pre-emptive investment.

If demand uncertainty is the reason for capacity withholding, applying an MO provision is unambiguously weakly welfare decreasing. The analysis parallels the peak-load pricing literature and includes the case of demand variability. An MO provision sets incentives to reduce invested capacity; the MO provision increases welfare in periods of low demand but at the expense of higher foregone welfare in periods of high demand. Given that uncertainty is a reason for unregulated MTI in the first place, this argument seems to be particularly relevant.

If interconnector demand is growing, then an MO provision delays the welfareenhancing investment and reduces capacity. Numerical analysis suggests that this will decrease welfare. As the fear of under-investment is a main reason for allowing unregulated MTI, having a policy which delays the investment appears inconsistent.

If strategic pre-emptive investment (to deter the building of a second line) is a risk, the welfare effects of an MO provision are ambiguous and depend on the relative fixed costs of building the line. For sufficiently large fixed costs, an MO provision has no effect. For sufficiently small fixed costs, the MO provision will makes ex post threat of using all capacity credible beyond the level that would otherwise not be credible without the MO provision. Within this range, for relatively large fixed costs, the MO provision decreases welfare (deterring entry would be welfare decreasing), and for relatively small fixed costs, welfare will increase (because entry deterrence with MO increases welfare).

We also investigated the case of incumbent market power on the importing energy market and where the line would compete with domestic producers. The new issue is that the 
market power in the importing energy market drives a wedge between price and costs. As a result a merchant interconnector might profitably import power that is more expensive than domestic power. The line has both a competitive effect (reducing domestic allocative inefficiency) and an import effect (which may displace cheaper power). The overall welfare effect may be positive or negative, depending on the relative costs. Assuming uncertainty (or variability) in import costs, we find that the MO provision somewhat surprisingly (weakly) lowers welfare. Finally, the social welfare maximising capacity can be larger or smaller than the profit maximising capacity, reflecting the trade-off between the effect of increased competition and expensive imports.

Overall, our investigations suggest that the new EU Regulation on Cross-Border Exchanges is unhelpful in requiring an MO provision regardless of the particular circumstances of the case. If a simple rule is required, it would seem better not to require an MO provision, but leave it to the regulator to decide what additional conditions, if any, to place on merchant interconnectors. In the presence of market power, such interconnectors should in any case be subject to a regulatory test, and that is the natural moment at which to define the regulatory regime affecting the interconnector.

The question of how to improve the social benefits of MTI undoubtably deserves further investigation. Tender auctions for various forms of capacity and contracts are increasingly being used in the electricity industry, and their design is increasingly recognised as critical to their success (Gilbert, Neuhoff and Newbery, 2004). The problem here is how to reward entrepreneurs who invest perhaps considerable resources in identifying attractive investment opportunities that have previously been overlooked, with a desire to reap maximum social value from exploiting the opportunity. As with patent protection, it may be necessary to accept some allocative inefficiency from the exercise of market power in order to induce the discovery of socially useful opportunities. 


\section{REFERENCES}

ACCC, 2001, Amendments to the National Electricity Code: Network pricing and market network service providers, File no. C1999/441, Sept. 21, 2001, ACCC.

Brunekreeft, G., 2002, 'Regulation and third party discrimination in the German electricity supply industry', European Journal of Law and Economics, Vol.13, No 2, pp. 203220.

Brunekreeft, G., 2004, 'Market-based investment in electricity transmission networks: Controllable flow', Utilities Policy, Vol. 12, pp. 269-281.

Brunekreeft, G., 2005, 'Regulatory issues in merchant transmission investment:', Utilities Policy, Vol. 13, No. 2, pp. 175-186.

Bushnell, J.B. \& Stoft, S.E., 1996, 'Electric grid investment under a contract network regime', Journal of Regulatory Economics, Vol. 10, pp. 61-79.

Dasgupta, P. \& Stiglitz, J.E., 1980, 'Uncertainty, industrial structure and the speed of R\&D', Bell Journal of Economics, Vol. 11, pp. 1-8.

Dixit, A., 1980, 'The role of investment in entry-deterrence', Economic Journal, Vol. 90, pp. 95-106.

Eaton, B. \& Ware, R., 1987, 'A theory of market structure with sequential entry', RAND Journal of Economics, Vol. 18, pp. 1-16.

EC, 2003, Regulation (EC) No 1228/2003 of 26 June 2003 on conditions for access to the network for cross-border exchanges in electricity, OJ. L176/1, 15.07.2003, European Commission, Brussels.

Gans, J.S. \& King, S.P., 2003, 'Access holidays for network infrastructure investment', Agenda, Vol. 10, No. 2, pp. 163-178.

Gans, J.S. \& King, S.P., 2004, 'Access holidays and the timing of infrastructure investment', Economic Record Vol. 80 (248), pp.89-100

Gilbert, R., 1989, "Mobility barriers and the value of incumbency", in: Schmalensee, $R$. \& Willig, R.D. (eds.), 1989, Handbook of Industrial Organization, pp. 475-535, NorthHolland.

Gilbert, R., Neuhoff, K. \& Newbery, D.N., 2004, 'Allocating transmission to mitigate market power in electricity networks', RAND Journal of Economics, Vol 35, no.41, pp. 691709.

Gilbert, R. \& Newbery, D.N., 1982, 'Preemptive patenting and the persistence of monopoly', American Economic Review, Vol. 72, pp. 514-526.

Gilbert, R. \& Newbery, D.N., 1994, 'The dynamic efficiency of regulatory constitutions', RAND Journal of Economics, Vol. 25, No. 4, pp. 538-554.

Grossman, S.I. \& Hart, O.D.,1980, 'Takeover bids, the free rider problem, and the theory of corporation', Bell Journal of Economics, Vol. 11, pp. 42-64.

Harvey, S.M. \& Hogan, W.W., 2001, 'Market power and withholding', mimeo, Harvard University, http://www.ksg.harvard.edu/hepg/.

Helm, D. \& Thompson, D., 1991, 'Privatised transport infrastructure and incentives to invest', Journal of Transport Economics and Policy, Vol. 25, pp. 231-246. 
Hogan, W.W., 2003, 'Transmission market design', presented at Electricity Deregulation: Where to from here? Conference at Texas A\&M University, April $4^{\text {th }}, 2003$.

Joskow, P.L. \& Tirole, J., 2000, 'Transmission rights and market power on electric power networks', RAND Journal of Economics, Vol. 31, No. 3, pp. 450-487.

Joskow, P.L. \& Tirole, J., 2005, 'Merchant transmission investment', Journal of Industrial Economics, Vol. 53, pp. 233-264.

Katz, M.L. \& Shapiro, C.,1987, 'R and D rivalry with licensing or imitation', American Economic Review, Vol. 77, No. 3, pp. 402-420.

Kristiansen, T. \& Rosellón, J., 2003, “A merchant mechanism for electricity transmission expansion", mimeo, HEPG, Harvard University.

McDaniel, T. and Neuhoff, K., 2004, 'Auctions of Gas Transmission Access: the British Experience,' in Auctioning Public Assets: Analysis and Alternatives, ed. M.C.W. Janssen, Cambridge CUP,.

Newbery, D.M. and T. McDaniel, T., 2003, 'Auctions and Trading In Energy Markets - An Economic Analysis', Ch 10, pp195-234 in CRI Regulatory Review2002/2003 P. Vass (ed.) (ISBN 185790 1142) Bath: Centre for the Study of Regulated Industries.

Newbery, D.N., Von der Fehr, N.-H. \& Van Damme, E., 2003, UK-Netherlands DC Interconnector, MSC DTe, The Hague.

Perry, M.K., 1989, 'Vertical integration, determinants and effects', in: Schmalensee, R. \& Willig, R.D. (eds.), 1989, Handbook of Industrial Organization, Vol. I, Ch. 4, pp. 183255.

Rosellón, J., 2003, 'Different approaches towards electricity transmission expansion,' Review of Network Economics, Vol. 2, No. 3, pp 238-269.

Steiner P.O., 1957, "Peak loads and efficient pricing", Quarterly Journal of Economics, Vol. 71, pp. 585-610.

Weiszäcker, C.C. von, 1980, 'A welfare analysis of barriers to entry', Bell Journal of Economics, Vol. 11, pp. 399-420 


\section{APPENDIX}

\section{The derivation of optimal $T$ and $K$ in section 2.2}

The investor chooses $K, T$ to maximise (15). The first order conditions are

$$
\begin{gathered}
\frac{\partial \pi}{\partial T}=e^{-r T}\left(b e^{-g T} K^{2}-(a-\beta) K+F\right)=0, \\
\frac{\partial \pi}{\partial K}=\int_{T}^{\infty}(a(t)-\beta-2 b K) e^{-r t} d t=0,
\end{gathered}
$$

whence

$$
K(T)=\frac{\int_{T}^{\infty}(a-\beta) e^{-r t} d t}{2 b \int_{T}^{\infty} e^{-(r+g) t} d t}=\frac{r+g}{r} \cdot \frac{a-\beta}{2 b} e^{g T} .
$$

This can be solved for $K$ and $T$ using (A2) to give (15) and (16).

Derivation of the social optimum in zero price initial period in section 2.2

Substituting for $Q(t)$ from (20) in (19) gives

$$
W(K, T)=\frac{a^{2}}{2 b} \int_{T}^{M} e^{-(r-g) t} d t+\int_{M}^{\infty}\left(a K-\frac{1}{2} b e^{-g t} K^{2}\right) e^{-r t} d t-(\beta K+F) \frac{e^{-r T}}{r} .
$$

where $M$ is determined by $K$. The first order conditions for $T$ and $K$ can now be found:

$$
\frac{\partial W}{\partial T}=-e^{-r T}\left(\frac{a^{2} e^{g T}}{2 b}-\beta K-F\right)=0, \therefore \beta K=\frac{a^{2} e^{g T}}{2 b}-F .
$$

The choice of $K$ is given by

$$
\frac{\partial W}{\partial K}=\int_{M}^{\infty}\left(a-b e^{-g t} K\right) e^{-r t} d t-\frac{\beta e^{-r T}}{r}=0,
$$

whence

$$
K(T)=\frac{r+g}{r} \frac{e^{g M}}{b}\left(a-\beta e^{-r(T-M)}\right)=\frac{r+g}{r a} K(T)\left\{a-\beta e^{-r T}\left(\frac{b K}{a}\right)^{r / g}\right\},
$$

or 


$$
\beta K(T)=\frac{\beta a}{b}\left(\frac{a g}{\beta(r+g)}\right)^{g / r} \cdot e^{g T}=\frac{a^{2} e^{g T}}{2 b}-F
$$

These equations can be solved to give the socially optimal values $K^{*}, T^{*}$ of (17) and (18).

The second case of under-used capacity holds provided $M>T$. From (21) and (23) this requires

$$
K * *=\frac{2 F \theta}{a-2 \beta \theta}=\frac{a e^{g M}}{b}>\frac{a e^{g T^{*}}}{b}=\frac{2 F}{a-2 \beta \theta} \text {, i.e. } \theta>1 \text {. }
$$

This is equivalent to

$$
\frac{r+g}{g}<\frac{a}{\beta}>2 \theta
$$

where the second inequality comes from the requirement for the investment data and amount to be positive.

\section{Proof of proposition 5 in section 3}

The derivative of $\Delta W$ with respect to $c$ is proportional to

$$
\left(6 n^{2}+12 n-8\right) a+2\left(n^{3}+8\right) c-2\left(n^{3}+3 n^{2}+6 n+4\right)(m+\beta),
$$

and since $a=c+\varepsilon$ for $\varepsilon>0$ from (38), (A11) is positive if

$$
\left(2 n^{2}+6 n-4\right) \mathcal{E}+\left(n^{3}+3 n^{2}+6 n+4\right)(c-m-\beta)>0
$$

This will be the case for $c>c^{* *}$ for some $c^{* *}$. That in turn ensures that there exists a $c^{*}, c^{* *<}$ $c^{*}<m+\beta$, such that $\Delta W=0$.

QED.

\section{Proof to proposition 6 in section 3}

We have to prove that

$$
S W^{w} \geq S W^{N}
$$

(where the superscripts refer to capacity Withholding and No capacity withholding). This can be rewritten as: 


$$
E C S+\frac{1}{2} E \pi_{I}+E \pi_{G} \geq C S^{N}+\frac{1}{2} \pi_{I}^{N}+\pi_{G}^{N}
$$

where $C S$ is consumer surplus and $\pi_{G}$ is the aggregate for all $n$ generators. The difference in consumer surplus is

$$
\frac{1}{2}\left(\alpha_{L}\left(a-p_{L}\right)\left(Q_{L}+n q_{L}\right)+\alpha_{H}\left(a-p_{H}\right)\left(Q_{H}+n q_{H}\right)-\left(a-p^{N}\right)(Q+n q)^{N}\right) .
$$

From Lemma 1 this is:

$$
\frac{1}{2}\left\lfloor p^{N}(Q+n q)^{N}-\alpha_{L} p_{L}\left(Q_{L}+n q_{L}\right)-\alpha_{H} p_{H}\left(Q_{H}+n q_{H}\right)\right]
$$

which is positive if $p$ and $(Q+n q)$ are negatively correlated, which holds because demand is downward sloping. Thus the net effect of capacity withholding on $C S$ is positive.

Clearly the profits of the interconnector are always weakly higher under capacity withholding than under MO, otherwise the firm would not withhold capacity. The profits of the generators are also weakly higher under capacity withholding than under an MO provision. Capacity withholding has an effect on generator output via the interconnector output and price; the generators do not withhold capacity themselves.

$$
\alpha_{L}\left(p_{L}-c\right) q_{L}+\alpha_{H}\left(p_{H}-c\right) q_{H} \geq\left(p^{N}-c\right) q^{N}
$$

which simplifies to:

$$
\alpha_{L} p_{L} q_{L}+\alpha_{H} p_{H} q_{H} \geq p^{N} q^{N}
$$

which, using Lemma 3, holds if $p$ and $q$ are positively correlated. From downward-sloping demand and the generators' reaction function ((38), which is inversely related to the Interconnector's output), this is the case. 